University of Nebraska - Lincoln

DigitalCommons@University of Nebraska - Lincoln

Michigan Bovine Tuberculosis Bibliography and

Database

Wildlife Disease and Zoonotics

2006

\title{
Wildlife Tuberculosis in South African Conservation Areas: Implications and Challenges
}

\author{
A.L. Michel \\ Department of Bacteriology, ARC-Onderstepoort Veterinary Institute, Private Bag x05, Onderstepoort \\ 0110, South Africa \\ R.G. Bengis \\ Directorate Veterinary Services, Skukuza, P.O. Box 138, South Africa \\ D.F. Keet \\ Directorate Veterinary Services, Skukuza, P.O. Box 138, South Africa \\ M. Hofmeyr \\ South African National Parks, Skukuza, P.O. Box 402, South Africa \\ L.M. de Klerk \\ South African National Parks, Skukuza, P.O. Box 402, South Africa \\ See next page for additional authors
}

Follow this and additional works at: https://digitalcommons.unl.edu/michbovinetb

Part of the Veterinary Medicine Commons

Michel, A.L.; Bengis, R.G.; Keet, D.F.; Hofmeyr, M.; de Klerk, L.M.; Cross, P.C.; Jolles, A.E.; Cooper, D.; Whyte, I.J.; Buss, P.; and Godfroid, J., "Wildlife Tuberculosis in South African Conservation Areas: Implications and Challenges" (2006). Michigan Bovine Tuberculosis Bibliography and Database. 44.

https://digitalcommons.unl.edu/michbovinetb/44

This Article is brought to you for free and open access by the Wildlife Disease and Zoonotics at DigitalCommons@University of Nebraska - Lincoln. It has been accepted for inclusion in Michigan Bovine Tuberculosis Bibliography and Database by an authorized administrator of DigitalCommons@University of Nebraska Lincoln. 


\section{Authors}

A.L. Michel, R.G. Bengis, D.F. Keet, M. Hofmeyr, L.M. de Klerk, P.C. Cross, A.E. Jolles, D. Cooper, I.J. Whyte, P. Buss, and J. Godfroid 


\title{
Wildlife tuberculosis in South African conservation areas: Implications and challenges
}

\author{
A.L. Michel $^{\text {a,* }}$, R.G. Bengis ${ }^{\text {b }}$, D.F. Keet ${ }^{b}$, M. Hofmeyr ${ }^{c}$, L.M. de Klerk ${ }^{c}$, \\ P.C. Cross ${ }^{d}$, A.E. Jolles ${ }^{\text {e }}$, D. Cooper ${ }^{\text {f }}$, I.J. Whyte ${ }^{c}$, P. Buss ${ }^{c}$, J. Godfroid ${ }^{\text {g }}$ \\ ${ }^{a}$ Department of Bacteriology, ARC-Onderstepoort Veterinary Institute, Private Bag x05, Onderstepoort 0110, South Africa \\ ${ }^{\mathrm{b}}$ Directorate Veterinary Services, Skukuza, P.O. Box 138, South Africa \\ ${ }^{\mathrm{c}}$ South African National Parks, Skukuza, P.O. Box 402, South Africa \\ ${ }^{\mathrm{d}}$ US Geological Survey, Northern Rocky Mountain Science Center, 229 AJM, Johnson Hall, Bozeman, MT 59717, USA \\ ${ }^{\mathrm{e}}$ Department of Ecology and Evolutionary Biology, Princeton University, USA \\ ${ }^{\mathrm{f}}$ Chief Veterinarian, Ezemvelo KwaZulu/Natal Wildlife - KZN Wildlife, Private Bag x01, St Lucia, 3936, South Africa \\ ${ }^{\mathrm{g}}$ Department of Veterinary Tropical Diseases, Faculty of Veterinary Science, University of Pretoria, \\ Private Bag x04, Onderstepoort 0110, South Africa
}

\begin{abstract}
Tuberculosis, caused by Mycobacterium bovis, was first diagnosed in African buffalo in South Africa's Kruger National Park in 1990. Over the past 15 years the disease has spread northwards leaving only the most northern buffalo herds unaffected. Evidence suggests that 10 other small and large mammalian species, including large predators, are spillover hosts. Wildlife tuberculosis has also been diagnosed in several adjacent private game reserves and in the Hluhluwe-iMfolozi Park, the third largest game reserve in South Africa.

The tuberculosis epidemic has a number of implications, for which the full effect of some might only be seen in the longterm. Potential negative long-term effects on the population dynamics of certain social animal species and the direct threat for the survival of endangered species pose particular problems for wildlife conservationists. On the other hand, the risk of spillover infection to neighboring communal cattle raises concerns about human health at the wildlife-livestock-human interface, not only along the western boundary of Kruger National Park, but also with regards to the joint development of the Greater Limpopo Transfrontier Conservation Area with Zimbabwe and Mozambique. From an economic point of view, wildlife tuberculosis has resulted in national and international trade restrictions for affected species. The lack of diagnostic tools for most species and the absence of an effective vaccine make it currently impossible to contain and control this disease within an infected free-ranging ecosystem. Veterinary researchers and policy-makers have recognized the need to intensify research on this disease and the need to develop tools for control, initially targeting buffalo and lion.
\end{abstract}

(C) 2005 Elsevier B.V. All rights reserved.

Keywords: Mycobacterium bovis; African wildlife; Epidemiology; Wildlife-livestock-human interface

* Corresponding author. Tel.: +27 12 5299384; fax: +27 125299127.

E-mail address: MichelA@arc.agric.za (A.L. Michel).

0378-1135/\$ - see front matter (C) 2005 Elsevier B.V. All rights reserved. doi:10.1016/j.vetmic.2005.11.035

This article is a U.S. government work, and is not subject to copyright in the United States. 


\section{Introduction}

A number of reports of tuberculosis, caused by Mycobacterium bovis, in free-ranging African wildlife during the 20th century illustrate the susceptibility of a wide range of free-ranging mammals to this disease which has been primarily recognized as a disease of livestock (Thorburn and Thomas, 1940; Francis, 1957; Guilbride et al., 1963; Gallagher et al., 1972). Some affected species, including African buffalo in the Queen Elizabeth National Park in Uganda and Lechwe in Zambia's Kafue National Park, proved to act as maintenance host for M. bovis (Woodford, 1972; Krauss et al., 1984).

In 1880, Hutcheon made the first reference of bovine tuberculosis, which is caused by infection with Mycobacterium bovis, in cattle in South Africa. It is most likely that the disease was introduced by imported European cattle breeds mainly during the 18th and 19th centuries. A potential link between tuberculosis in livestock and game was first suggested by Paine and Martinaglia in 1929 when they reported bovine tuberculosis in kudu and small ungulates in the Eastern Cape Province of South Africa. Subsequently, the increasing economic importance of tuberculosis as a disease of cattle led to the implementation of a national bovine tuberculosis control and eradication scheme in South Africa in 1969 (Huchzermeyer et al., 1994). Retrospective outbreak investigations suggested that the disease was transmitted to buffalo in Kruger National Park (KNP) from domestic cattle in the southeast corner of KNP between 1950 and 1960 (Kloeck, 1998). The Crocodile River formed a natural barrier between KNP and the farmland to the south, but sightings of buffalo and cattle grazing in close proximity of one another were not uncommon. The presence of the disease was, however, only discovered in 1990. In 1992, the prevalence of bovine tuberculosis was estimated to be $0,4.4$ and $27.1 \%$ in the north, central and south zones, respectively. Spread of infection to lion, cheetah, kudu, leopard and chacma baboon became evident by 1995 (Keet et al., 1996, 2000). By 1998 the prevalence of bovine tuberculosis had increased significantly to 16 and $38.2 \%$ in the central and south zones, due to increases in both the average herd prevalence and the total number of herds infected with bovine tuberculosis (Rodwell et al., 2000). In the Hluhluwe-iMfolozi Park (HiP), bovine
Table 1

Wildlife species in which $M$. bovis infection has been confirmed to date in South Africa

African buffalo (Syncerus caffer)

Greater kudu (Tragelaphus strepsiceros)

Lion (Panthera leo)

Eland (Taurotragus oryx)

Warthog (Phacochoerus aethiopicus)

Bushpig (Potamochoerus porcus)

Large spotted genet (Genetta tigrina)

Leopard (Panthera pardus)

Spotted hyaena (Crocuta crocuta)

Cheetah (Acinonyx jubatus)

Chacma baboon (Papio ursinus)

Impala (Aepyceros melampus)

Honey badger (Mellivora capensis)

tuberculosis was first diagnosed in buffalo in 1986 and spillover to lion, chacma baboon, bushpig and greater kudu was later documented. Bovine tuberculosis herd prevalence in HiP varies from $<10$ to $>40 \%$ (Jolles, 2004). In Table 1, all free-ranging species diagnosed with bovine tuberculosis in $\mathrm{HiP}, \mathrm{KNP}$ as well as adjacent reserves and farms are listed.

\section{Area descriptions}

\subsection{Kruger National Park}

Kruger National Park with an area of $19485 \mathrm{~km}^{2}$ is South Africa's largest wildlife refuge and a critical biodiversity resource. The Park's game population supports 147 mammal species, including approximately 27000 African buffalo and 1700 lions. Bordering on Zimbabwe to the north and Mozambique to the east, the KNP stretches $320 \mathrm{~km}$ from north to south and $65 \mathrm{~km}$ from east to west. More recently several private game reserves, situated on the western border, have been incorporated to form the Greater Kruger National Park Complex (GKNPC).

\subsection{Hluhluwe-iMfolozi Park}

The Hluhluwe-iMfolozi Park is situated in the province of Kwazulu/Natal and is South Africa's third largest game reserve. It covers an area of almost 100000 ha. HiP has a buffalo population of approximately 3000 and is entirely surrounded by communal farm land. 


\section{Implications of bovine tuberculosis}

\subsection{Effect on wildlife populations}

African buffalo can act as maintenance host of M. bovis and propagate bovine tuberculosis in large ecosystems in the absence of cattle (de Vos et al., 2001). Their social behaviour provides favourable conditions for aerosol transmission of $M$. bovis to members of the same herd. Buffalo herds in the Kruger National Park range in size from 50 to 1000 individuals with an average of roughly 250 . In addition, males frequently disperse between herds via bachelor groups, while females and juveniles move to different herds via splinter groups (Halley et al., 2002; Cross et al., 2005a). Recent studies showed that these events may occur more frequently than previously thought, promoting the spatial spread of M. bovis (Cross et al., 2004, 2005a). Cross et al. (2005b) described how drought conditions may favour spatial spread of the disease by prompting herds to explore new areas and mix with previously unassociated herds. In HiP, buffalo bulls spent only a limited period, generally not exceeding 3-4 months, with breeding herds, but their $M$. bovis infection rates were higher than those of cows (Jolles, 2004).

On examination of mortality rates and calf:cow ratios in both infected and non-infected buffalo in HiP, Jolles et al. (2005) found that mortalities due to clinically advanced bovine tuberculosis occurred at an annual rate of $11 \%$. Over time this is expected to shift the age distribution towards younger animals. On the other hand, bovine tuberculosis was found to reduce pregnancy rates in infected females which has an opposite effect on age distribution. As a result, bovine tuberculosis may have no overall affect upon the age structure of the buffalo population. Due to the chronic nature of bovine tuberculosis and the long lifespan of African buffalo, it is not surprising that results from studies conducted earlier in the epidemic may differ from those conducted later, and some effects may only be detectable later in the epidemic. Results from a cross-sectional survey in 1998 by Rodwell et al. (2001) suggested that bovine tuberculosis may have no effect on buffalo fecundity, while data from HiP (Jolles, 2004) and a later study of known individuals from 2001 to 2005 suggest otherwise (Cross, unpublished data).
Caron et al. (2003) found a compelling correlation between increasing bovine tuberculosis herd prevalence in buffalo and a decrease in overall body condition. The association was even stronger during the dry season when herds of higher prevalence lost condition faster than herds of low bovine tuberculosis prevalence. Weak, old and debilitated prey animals are more vulnerable to predation by lions and other large predators (Mills et al., 1995; Funston, 1998). Hence buffalo worst affected by the disease are the most likely targeted during lion predation because they are easiest to kill (Caron et al., 2003).

Since buffalo are considered to be one of four preferential prey species of lions (Mills, 1995), the frequent exposure of lions to large amounts of infectious buffalo tissue led to a spatial spread of bovine tuberculosis within lion prides in areas where the prevalence of bovine tuberculosis is high in buffalo (Keet, unpublished data). It is thus difficult to determine at present whether lions are a maintenance or spillover host. Although infection occurs predominantly via the oral route, sociality and intra-species aggression between lions are specific behaviour patterns that may facilitate and predispose to aerosol and percutaneous transmission. The role of these horizontal and possibly of vertical transmission in perpetuating the infection cannot be excluded sufficiently. In a study comparing identified lion prides in the high buffalo TB prevalence zone, with a similar cohort in the low TB buffalo prevalence zone, disease effect parameters determined for buffalo were found to be true for infected lions. These include disease mortality, correlations between age and infection with bovine tuberculosis as well as between infection and body condition. Further and probably even more importantly, bovine tuberculosis was found to be driving social changes within prides which contributed to lower lion survival and breeding success (Keet, unpublished data). A faster territorial male coalition turnover was seen with consequent infanticide. The eviction of entire male and female prides from territories was also documented. This is in total contradiction with lion behaviour patterns described from elsewhere in Kruger and the rest of Africa. An abnormal sex ratio was seen-two males for every female (adults). It should be one male for every two females. The infected sub-population was significantly younger that the non-infected sub-population. 
The non-infected sub-population lived significantly longer than the infected sub-population, especially males. Cub survival was higher in the non-infected sub-population but birth rate was higher in the infected sub-population (Keet, unpublished data).

Research conducted in South Africa and elsewhere shows that infected buffalo serve as a source of direct infection to large predators and scavenging omnivores. A less obvious link in the transmission between the maintenance and spillover host not living in the same habitat, has been demonstrated in greater kudu (Michel, 2002). The M. bovis genotype commonly found in KNP buffalo has been isolated from kudu, suggesting either faecal-oral transmission as discussed by previous authors (Thorburn and Thomas, 1940), or alternatively, infection could have been carried over by ingestion of contaminated browse or water. More often an $M$. bovis strain genetically unrelated to the one characterized in buffalo, was associated exclusively with tuberculosis in KNP kudu, strongly indicating the maintenance host potential of this species. Cooper (unpublished data) concluded that a resident population of greater kudu were the most likely source of bovine tuberculosis infection in previously disease-free buffalo one year after they had been introduced into a Kwazulu/Natal game reserve.

The source of recurrent infections in solitary predators such as cheetah and leopard is only partially understood. We have numerous observations where cheetahs and leopards were scavenging and it has been confirmed that they were infected with the same $M$. bovis genotype as buffalo (Michel, unpublished data). A possibility remains that they contract bovine tuberculosis from a currently undiagnosed infection in a smaller antelope species. Other carnivores such as hyaenas, as well as certain omnivores (baboons, warthogs and honey badgers) are considered to contract $M$. bovis through scavenging on bovine tuberculosis infected carcasses (Bengis, unpublished data). Greater kudu appear to be the only species which show distinct clinical signs of bovine tuberculosis characterized by bilateral abscessation of parotid lymph nodes, frequently accompanied by formation of draining fistulae (Keet et al., 2001).

With the exception of greater kudu, none of the infected species known to date has shown maintenance host potential. However, as bovine tuberculosis prevalence continues to increase there is also a greater risk of spillover to new vulnerable and rare species.

\subsection{The wildlife-livestock-human interface}

The farmland on the $390 \mathrm{~km}$ long western border of GKNPC is largely under communal land use. The livelihood of rural communities relies to a large extend on livestock farming. A game deterrent fence separates the two landscapes, but despite great efforts and costs for its maintenance this man-made barrier cannot guarantee the absolute separation of livestock from infected wildlife populations. Elephant activities or natural disasters such as the water floods experienced early in the year 2000, can cause damage to the fence, allowing buffalo to mingle with domestic cattle. On the other hand, fences cannot prevent the movement of wild animals in all cases, e.g. greater kudu and warthogs. Once contact between infected wild animals with livestock is established, the potential of $M$. bovis transmission to cattle exists, as demonstrated in New Zealand and Great Britain and North America (Cheeseman et al., 1989; Morris and Pfeifer, 1994).

To date no evidence of outbreaks of bovine tuberculosis in communal cattle herds has been demonstrated, despite intensified monitoring of cattle health at the interface (du Plessis, pers. comm.). However, unlike in commercial productions, communal livestock and their products are largely excluded from veterinary and veterinary public health control measures (Michel et al., 2004). Infection of communal cattle with bovine tuberculosis could be detrimental to the livelihood of small scale farmers. The objectives of livestock keeping in rural areas of sub-Saharan Africa, over and above that of food production, also include the generation of traditional wealth, social status and marriage dowries. As a result of this value system, life expectancy of livestock is generally higher than on commercial farms, livestock are moved in exchange of goods or services, and owners often live in close proximity with their animals. Bovine tuberculosis as a chronic and progressive disease manifests itself more often in older animals, under nutritional or productive stress. Taking this into account, people who are frequently exposed to either livestock infected with bovine tuberculosis or infected products such as unpasteurised milk, should be considered at risk of 
contracting zoonotic tuberculosis. This risk increases considerably in individuals with an immuno-suppression induced by HIV infection, as documented previously (Raviglione et al., 1995). A report published in South Africa in 2001 stated the overall HIV prevalence in this country at between $15 \%$ (total prevalence) and 30\% (age group 30-34 years) (Dorrington et al., 2001). At the end of 2003, an estimated 5.3 million South Africans were living with HIV. As a result of the HIV epidemic the crude incidence rate of human tuberculosis has not only increased drastically (Cosivi et al., 1998) but $50 \%$ or more of new cases of tuberculosis in South Africa can be ascribed to prior infection with HIV (Maartens, 2001). In Hlabisa Hospital, situated in rural Kwazulu/ Natal close to the HiP, the number of African HIVpositive patients with tuberculosis increased from six in 1989 to 451 as early as in 1993 (Walker et al., 2003). Although the role of zoonotic tuberculosis in humans has not been investigated in South Africa, the wildlifelivestock-human interface as a risk factor should not be underestimated.

\subsection{Implications on conservation and trade}

The diagnosis of bovine tuberculosis in a game species has severe implications on the national and international trade in wildlife due to movement restrictions and results in revenue losses for both KNP and HiP. It may be argued that bovine tuberculosis has partially turned the KNP into a conservation island thereby not only jeopardizing conservation efforts in endangered species but also prohibiting the free exchange of genetic resources between conservation areas.

\subsection{Greater Limpopo Transfrontier Conservation Area}

In December 2002 an international treaty to establish the Greater Limpopo Transfrontier National Park (GLTNP) was signed, bringing the parks of Gaza in Mozambique, Kruger National Park in South Africa and Gonarezhou in Zimbabwe together under a joint management. The three countries also reached agreement on creating a transfrontier conservation area (TFCA) that encompasses the GLTNP and the intervening matrix of conservancies and wildlife ranches on freehold land, together with the communal farming areas. Covering an area of approximately $100000 \mathrm{~km}^{2}$, the Greater Limpopo Transfrontier Conservation Area (GLTFCA) will be the second transfrontier park in southern Africa and one of the biggest conservation areas in the world. The longer term plans for this vast area currently focus on the development of wildlife-based tourism with freedom of movement for wildlife and tourists across international borders. Interactions between wildlife, livestock and humans living in the conservation area can be expected to increase drastically. The management of wildlife and livestock diseases such as bovine tuberculosis within the individual parks and the envisaged larger landscape has remained unresolved and presents a new challenge on approaches to disease control with an impact on existing disease control policies. Currently efforts are undertaken to gain information on geographical distribution and prevalence rates of bovine tuberculosis in domestic and wild species in the countries concerned. The need for an integrated, interdisciplinary approach on animal health issues including bovine tuberculosis has been identified in a framework document by the AHEAD Working Groups (Osofsky et al., 2005).

\section{Progress}

\subsection{Surveillance and monitoring}

In the absence of a management strategy policy for bovine tuberculosis in KNP buffalo, resources have been focussed on surveillance projects to determine the distribution and rate of spread of the disease. A progressive northward spread of bovine tuberculosis as well as an increase in disease prevalence have been documented. A monitoring project in buffalo in a dedicated study area in the medium prevalence zone revealed that the prevalence of bovine tuberculosis increased in this sub-population from $13 \%$ in 2001 to $25 \%$ in 2003. For minimal invasiveness as well as ethical and ecological considerations, both surveys in the low prevalence north zone were based on live sampling making use of the modified gamma interferon assay as described by Grobler et al. (2002). In 2000, the infection had spread to an 
additional three herds. By 2003, a total of 10 out of 29 buffalo herds in the northern region of KNP had a culture-confirmed positive bovine tuberculosis status. Up to date the status of two further herds has remained suspect after positive interferon- $\gamma$ test results for one buffalo in either herd could not be confirmed (Hofmeyr, unpublished data). In 2004, the most northern case of bovine tuberculosis in buffalo was diagnosed approximately $40 \mathrm{~km}$ south of the Limpopo River, which forms the border between South Africa and Zimbabwe (Hofmeyr, unpublished data).

In Kwazulu/Natal a control programme for managing bovine tuberculosis in HiP was initiated in 1999 which is currently ongoing. The programme is aimed at reducing buffalo herd prevalence below $10 \%$, as well as reducing the risk of spillover into key species and to domestic livestock in areas surrounding the park. It is based on limited intervention in the form of mass capture of buffalo followed by tuberculin testing and removal of positive animals which appears to help reduce the prevalence of infection in individual herds (Cooper, unpublished data). To date a total of 4431 tests have been performed on buffalo identifying 850 reactors. The programme was successful in reducing the prevalence in some buffalo herds from previously $10-20 \%$ to below $10 \%$, and in high prevalence herds from approximately $55 \%$ in 2000/2001 to an estimated 20-30\% (Jolles and Cooper, unpublished data).

Laboratory diagnosis of suspect cases of bovine tuberculosis in wildlife is essential for confirmation of infection and, in combination with molecular characterization of M. bovis, provides a powerful tool to assist in studying spatial, temporal and inter-species transmission of $M$. bovis. Restriction fragment length polymorphism has been used to track transmission from cattle to KNP buffalo, from buffalo to lion and other spillover species (Michel, 2002). At present, results from the genetic analysis of $M$. bovis isolates from most of the infected species support the hypothesis that the bovine tuberculosis epidemic originated from a point source and subsequently spread through the park. In contrast, at least two epidemiologically unrelated $M$. bovis strains were found to circulate in $\mathrm{HiP}$ buffalo. The bovine tuberculosis epidemics in KNP and HiP were shown to be epidemiologically unrelated. Genotying of $M$. bovis will become instrumental in the bovine tuberculosis control of the future transfrontier conservation area with Zimbabwe and Mozambique.

\subsection{Control}

Once bovine tuberculosis has established itself in a native, free-ranging maintenance host, eradication of the disease becomes highly unlikely. The choice of suitable control measures depends on the primary objectives for the particular ecosystem. KNP has an obligation to protect those species that host the pathogen. Although there is presently no evidence of a population level decline in the buffalo due to bovine tuberculosis (Whyte, 1998), various implications have to be considered which include the preservation of protected species, the minimization of risk of transmission to domestic cattle and a potentially devastating impact on population dynamics in other maintenance and spillover species. Vaccination is undisputedly the control measure of choice in achieving these objectives, but in the absence of an effective vaccine alternative strategies have to be decided upon. Currently bovine tuberculosis is managed in KNP with minimal interference, meaning that no active control efforts have been implemented, but surveillance, monitoring and research activities are conducted to investigate the major epidemiological determinants (de Lisle et al., 2001). This strategy is likely to change following the recent classification of bovine tuberculosis as an alien species in the KNP ecosystem (SANParks, unpublished information). The broad objective of the policy on alien species is to minimize the impact on, and maintain the integrity of indigenous biodiversity. Thresholds for potential concerns (TPCs) e.g. influence of the disease on biodiversity, the spatial and temporal impact of bovine tuberculosis on population dynamics, the animal and public health implications at the interface, etc. have been determined for bovine tuberculosis in buffalo and TPCs for other species, especially lions, are expected to be included over time. A monitoring programme has been proposed to determine whether and to what extent the thresholds have been reached or exceeded. This monitoring programme is linked to objectives of the Southern Africa Working Group of AHEAD (Animal Health for the Environment and Development) (http://www.wcs-ahead.org) and the veterinary research objectives of the Peace Parks Foundation, 
both of which are concerned with the socio-political and socio-economic aspects of this and other livestock diseases and the impact they may have at the wildlifelivestock-human interface in the GLTFCA.

Vaccination remains the ultimate control measure for bovine tuberculosis in wildlife reservoirs. Despite the close relatedness between domestic cattle and African buffalo it is mandatory that the effectiveness of potential vaccine candidates can be demonstrated in buffalo. To determine adequate infectious challenge doses, an infection model was developed in which a local M. bovis strain was used for intra-tonsillar infection of buffalo. Lesions induced were comparable in size, number and distribution to those found in naturally infected buffalo (de Klerk, unpublished data). The evaluation of BCG as a vaccine in African buffalo has recently commenced. Despite the fact that initial experiments did not yield statistically significant differences in the number of lesioned buffaloes between the groups of vaccinated and control animals, they have provided us with crucial insight instrumental to the design of subsequent trials.

For monitoring and control purposes, availability of reliable diagnostic tests for affected species is essential. Despite its many limitations in wildlife, the intradermal tuberculin test is currently used to diagnose bovine tuberculosis in buffalo and lions (Jolles et al., 2005; Keet, unpublished data). Following a slight modification, the bovine gamma interferon assay has proved to be a valuable alternative to the tuberculin test (Grobler et al., 2002). A project has recently been initiated to explore the potential of this technique for bovine tuberculosis testing in rhinoceros and elephants (Morar, 2003). For many other animal species, however, there are no ante mortem tests available to date and the diagnosis of $M$. bovis infection relies on culture and histopathology.

\section{Discussion}

Bovine tuberculosis is most well known as a disease of livestock and the role of wildlife reservoirs in its persistence has been recognized (Bengis et al., 1996; Schmitt et al., 2002). Countries' approaches to address and resolve this problem are largely determined by economic and socio-political driving forces. In the case of New Zealand, where the wildlife reservoir is considered an alien species, culling as a management option for bovine tuberculosis does not warrant ecological or ethical concerns. In contrast, wildlife tuberculosis in South and Southern Africa may, in the medium to long-term, threaten the viability of indigenous, protected and even endangered species in ecosystems such as the KNP and HiP. Although direct effects of bovine tuberculosis are difficult to detect and appear to be developing slowly at the species population level, research conducted in buffalo and lion has revealed distinct adverse effects of bovine tuberculosis on individual and sub-population level which cannot be ignored. Organisations with the responsibility to maintain biodiversity in these ecosystems have the obligation to protect species, regardless of or despite the fact that they may be hosts of bovine tuberculosis. Wildlife-based tourism and trade are important economic lifelines for South Africa and can be adversely affected by bovine tuberculosis. At the same time, governments have an obligation to protect human health at the interface of humans, domestic livestock and wildlife. The significance of zoonotic tuberculosis in humans in Southern Africa is currently unknown. In the light of the current HIV/AIDS burden, however, zoonotic tuberculosis should be considered a health risk factor in immuno-compromised people, since human tuberculosis is not only the commonest cause of HIVrelated deaths, but HIV infection is driving the tuberculosis epidemic in sub-Saharan Africa.

Whatever the current limitations are in terms of resources, effective bovine tuberculosis control measures, scientific information, research tools, etc., the development of the GLTFCA requires an understanding of the complex systems influencing both human livelihoods and wildlife health across international borders.

\section{Further challenges}

The pioneer work of Anderson and May paved the way for the study of wildlife disease ecology. They pointed out that the parasite-host relationship was not simply the impact a parasite had on an individual, but formed an integral part of those interactions at the population level and at the same time a dynamic process where parasites were flowing from one host to 
the next. The rate at which this took place was determined by host behaviour and abundance (Anderson and May, 1978). Nowadays, numerous workers apply these ideas to explore the impact of diseases in naturally fluctuating wildlife populations, particularly in the context of conservation biology. Therefore, a major challenge is to link our understanding of individual level of infections to how disease flows through susceptible host populations and may possibly influence host dynamics. Due to its importance and its sustainability in the population, bovine tuberculosis in buffalo highlights some of the challenges posed by bovine tuberculosis in wildlife to ecologists and veterinarians. In order to understand the epidemiology of bovine tuberculosis in the buffalo population, a fundamental parameter is the $R_{0}$ (' $R$ nought'), the basic reproductive number that defines a threshold $\left(R_{0}>1\right)$ for a pathogen to invade a population or the number of new infections arising from an infected individual. Obviously this parameter is linked to the density of the population allowing contact between susceptible and infected members (Hudson et al., 2002). In the buffalo population, the natural unit would be either a herd, or the number of individuals living in a defined geographical area.

Contradicting the often-presented hypothesis that M. tuberculosis evolved from M. bovis, recent work suggests that the common ancestor of the tubercle bacilli resembled $M$. tuberculosis and could well already have been a human pathogen (Brosch et al., 2002). Domestication of bovidae, in turn, allowed the adaptation of $M$. bovis to cattle. This study re-enforces the hypothesis of a recent introduction of $M$. bovis in buffalo related to the introduction of bovine tuberculosis infected cattle in Africa some 200 years ago and subsequent contact with naïve buffalo, 40 years ago (Bengis et al., 1996). As a consequence there has been no co-evolution between $M$. bovis and its new host and thus there are numerous unknowns in the short natural history of bovine tuberculosis in buffalo. Therefore, the pathobiology of the infection in buffalo has to be studied in detail, particularly immune responses, in order to ascertain that assumptions we make, based on our knowledge of the infection in cattle, are valid for buffalo, too. Critical questions like transmission of the infection, induced pathology and conditions prevailing for overt disease (and hence shedding and infectivity) in buffalo, have to be addressed. This can only be achieved by identifying the host immune responses that are likely to protect the host or conversely that are likely to promote invasion of the buffalo population by the newly introduced pathogen. Ecological immunology opens new avenues of research for invasion biology (Lee and Klasing, 2004): how do buffalo cope with the shift from native, co-adapted pathogens to a preponderance of a novel challenge and how does this affect the potential of $M$. bovis to become invasive? Based on the temporal distribution pattern following the entry of bovine tuberculosis into KNP it was suggested in 2000 that it could take another 30 years for the infection to reach the northern most point of KNP, but that due to a higher buffalo density the spread might occur faster (de Vos et al., 2001). In 2004, bovine tuberculosis was diagnosed in buffalo just $40 \mathrm{~km}$ from the northern boundary of KNP. Such a phenomenon cannot be easily explained by transposing our knowledge of the epidemiology of bovine tuberculosis in cattle to buffalo. Indeed, most (if not all) our recent knowledge of the epidemiology of bovine tuberculosis in cattle has been acquired in the context of control or eradication programs (Phillips et al., 2003). The epidemiology of bovine tuberculosis in buffalo is in essence different: there has been no co-evolution between the host and the newly introduced pathogen and no such control programs exist. Hence infection and disease are allowed to progress. Recent data suggest that bovine tuberculosis has invaded a vast proportion of the KNP buffalo population.

It is generally accepted that tuberculosis in humans results from a single infection with a single $M$. tuberculosis strain. Such infections are thought to confer protective immunity against exogenous reinfection. These assumptions were recently challenged. Indeed, a South African study published in 2004, showed that patients with active tuberculosis often have different strains in the same sputum specimen. These results suggest that multiple infections are frequent, implying high re-infection rates and the absence of efficient protective immunity conferred by the initial infection (Warren et al., 2004). What is the potential role of multiple infections in bovine tuberculosis, particularly in buffalo in KNP where no control program exists and where the infection pressure is high? Is overt disease (and as a consequence, the shedding of $M$. bovis) a result of 
progressive disease following infection acquired early in life, possibly after reactivation, or could it be due to multiple infections? Is a shift of dominance of a Th1 towards a Th2 immune response associated with the progression of the disease as recently suggested for cattle (Welsh et al., 2005)? Answers to these questions are critical in order to better understand the epidemiology of bovine tuberculosis in buffalo.

\section{Acknowledgements}

The authors are grateful to the South African Veterinary Foundation for funding of fundamental studies on bovine tuberculosis in lions and to the US NSF-NIH Ecology of Infectious Disease Grant for studies on the ecology of bovine tuberculosis in buffalo. We are grateful for financial assistance provided by the Smithsonian Institution for vaccine trials in buffalo and from the National Geographic Society, the Theresa Heinz Foundation, the Mellon Foundation and the Wildlife Conservation Society in support of research related to bovine tuberculosis buffalo in HiP.

\section{References}

Anderson, R.M., May, R.M., 1978. Regulation and stability of hostparasite population interactions. I. Regulatory processes. J. Anim. Ecol. 47, 219-247.

Bengis, R.G., Kriek, N.P.J., Keet, D.F., Raath, J.P., de Vos, V., Huchzermeyer, H., 1996. An outbreak of tuberculosis in a freeliving African buffalo (Syncerus caffer SPARRMAN) population in the Kruger National Park: a preliminary report. Onderstepoort J. Vet. Res. 63, 15-18.

Brosch, R., Gordon, S.V., Marmiesse, M., Brodin, P., Buchrieser, C., Eiglmeier, K., Garnier, T., Gutierrez, C., Hewinson, G., Kremer, K., Parsons, L.M., Pym, A.S., Samper, S., van Soolingen, D., Cole, S.T., 2002. A new evolutionary scenario for the Mycobacterium tuberculosis complex. Proc. Natl. Acad. Sci. U.S.A. 99, 3684-3689.

Caron, A., Cross, P.C., du Toit, J.T., 2003. Ecological implications of bovine tuberculosis in African buffalo herds. Ecol. Appl. 13, 1338-1345.

Cheeseman, C.L., Wilesmith, J.W., Stuart, F.A., 1989. Tuberculosis: the disease and its epidemiology in the badger-a review. Epidemiol. Infect. 103, 113-125.

Cosivi, O., Grange, J.M., Daborn, C.J., Raviglione, M.C., Fujikura, T., Cousins, D., Robinson, R.A., Huchzermeyer, H.F.A.K., de Kantor, I., Meslin, F.X., 1998. Zoonotic tuberculosis due to Mycobacterium bovis in developing countries. Emerg. Infect. Dis. 4, 59-70.
Cross, P.C., Lloyd-Smith, J.O., Bowers, J.A., Hay, C.T., Hofmeyr, M., Getz, W.M., 2004. Integrating association data and disease dynamics in a social ungulate: bovine tuberculosis in African buffalo in the Kruger National Park. Ann. Zool. Fennici 41, 879892.

Cross, P.C., Lloyd-Smith, J.O., Getz, W.M., 2005a. Disentangling association patterns in fission-fusion societies using African buffalo as an example. Anim. Behav. 69, 499-506.

Cross, P.C., Lloyd-Smith, J.O., Johnson, P.L.F., Getz, W.M., 2005 b. Duelling timescales of host movement and disease recovery determine invasion of disease in structured populations. Ecol. Lett. 8, 587-595.

de Lisle, G.W., Mackintosh, C.G., Bengis, R.G., 2001. Mycobacterium bovis in free living and captive wildlife, including farmed deer. Mycobacterial infections in domestic and wild animals. Rev. Sci. Tech. Off. Int. Epiz. 20, 86-111.

de Vos, V., Raath, J.P., Bengis, R.G., Kriek, N.J.P., Huchzermeyer, H., Keet, D.F., Michel, A., 2001. The epidemiology of tuberculosis in free-ranging African buffalo (Syncerus caffer) in the Kruger National Park, South Africa. Onderstepoort J. Vet. Res. 68, 119-130.

Dorrington, R., Bourne, D., Bradshaw, D., Laubscher, R., Timaeus, I.M., 2001. The impact of HIV/AIDS on adult mortality in South Africa. Technical Report of the Burden of Disease Research Unit of the Medical Research Council, South Africa.

Francis, J., 1957. Tuberculosis in Animals and Man. Cassell and Company Limited, London, pp. 3-10, 70-82.

Funston, P., 1998. Predator-prey relationships between lions and large ungulates in the Kruger National Park. Ph.D. Thesis. University of Pretoria, South Africa.

Gallagher, J., MacAdam, I., Sawyer, J., van Lavieren, L.P., 1972. Pulmonary tuberculosis in free living leche antelope in Zambia. Trop. Anim. Health Prod. 4, 204-213.

Grobler, D.G., Michel, A.L., de Klerk, L.-M., Bengis, R.G., 2002. The gamma interferon test: its usefulness in a bovine tuberculosis survey in African buffaloes (Syncerus caffer) in the Kruger National Park. Onderstepoort J. Vet. Res. 69, 221227.

Guilbride, P.D.L., Rollison, D.H.L., Mcanulty, E.G., Alley, J.G., Wells, E.A., 1963. Tuberculosis in free living African (Cape) buffalo (Syncerus caffer Sparrman). J. Comp. Path. Ther. 73, 337-348.

Halley, D.J., Vandewalle, M.E.J., Taolo, C., 2002. Herd-switching and long-distance dispersal in female African buffalo (Syncerus caffer). Afr. J. Ecol. 40, 97-99.

Hudson, P.J., Rizzoli, A., Grenfell, B.T., Heesterbeek, H., Dobson, A.P., 2002. The Ecology of Wildlife Diseases. Oxford University Press.

Huchzermeyer, H.F.A.K., Brueckner, G.K., van Heerden, A., Kleeberg, H.H., van Rensburg, I.B.J., Koen, P., Loveday, R.K., 1994. Tuberculosis. In: Coetzer, J.A.W., Thomson, G.R., Tustin, R.C. (Eds.), Infectious Diseases of Livestock. pp. 1425-1445.

Hutcheon, D., 1880. Tering: consumption, tables mesenterica. Annual Report. Colonial Veterinary Surgeon, Cape of Good Hope.

Jolles, 2004. Disease ecology of bovine tuberculosis in African buffalo. Ph.D. Thesis. Princeton University. 
Jolles, A.E., Cooper, D., Levin, S.A., 2005. Hidden effects of chronic tuberculosis in African buffalo. Ecology 86 (9), 2358-2364.

Keet, D.F., Kriek, N.P.J., Penrith, M.-L., Michel, A., Huchzermeyer, H., 1996. Tuberculosis in buffaloes (Syncerus caffer) in the Kruger National Park: Spread of the disease to other species. Onderstepoort J. Vet. Res. 63, 239-244.

Keet, D.F., Kriek, N.P.J., Bengis, R.G., Grobler, D.G., Michel, A.L., 2000. The rise and fall of tuberculosis in a free-ranging chacma baboon troop in the Kruger National Park. Onderstepoort J. Vet. Res. 67, 115-122.

Keet, D.F., Kriek, N.P.J., Bengis, R.G., Michel, A., 2001. Tuberculosis in kudus (Tragelaphus strepsiceros) in the Kruger National Park. Onderstepoort J. Vet. Res. 68, 225-230.

Kloeck, P.E., 1998. Tuberculosis of domestic animals in areas surrounding the Kruger National Park. In: Proceedings of the Challenges of Managing Tuberculosis in Wildlife in Southern Africa, Zunkel, July 30-31, Nelspruit, South Africa.

Krauss, H., Roetcher, D., Weiss, R., Danner, K., Hubschle, O.J.B., 1984. Wildtiere als Infektionsquelle fuer Nutztiere: Untersuchungen in Zambia. In: Beitraege der Klinischen Veterinaermedizin zur Verbesserung der tierischen Erzeugung in den Tropen, Band 10, Justus-Liebig-Universitaet, Giessen.

Lee, K.A., Klasing, K.C., 2004. A role for immunology in invasion biology. Trends Ecol. Evol. 19, 523-529.

Maartens, G., 2001. HIV and tuberculosis. In: Joint Congress on HIV Clinicians Infectious Diseases Infection Control Travel Medicine Sexually Transmitted Diseases Societies and Veterinary and Human Public Health, December 2-6, Stellenbosch, South Africa.

Michel, A.L., 2002. The epidemiology of M. bovis infection in South African wildlife.In: Abstracts of the Veterinary European Network on Mycobacterium (VENOM) Symposium: DNA Fingerprinting of Bovine TB strains, October 24-26, Belfast, Northern Ireland.

Michel, A.L., Meyer, S., McCrindle, C.M., Veary, C.M., 2004. Community based veterinary public health systems, current situation, future trends and recommendations. In: FAO Expert Consultation on Community Based Veterinary Public Health Systems. http://www.fao.org/ag/againfo/programmes/en/vph/ events/expert_consult_report.pdf.

Mills, M.G.L., 1995. Notes on wild dog (Lycaon pictus) and lion (Panthera leo) population. Trends during a drought in the Kruger National Park. Koedoe 38, 95-99.

Mills, M.G.L., Biggs, H.C., Whyte, I.J., 1995. The relationship between rainfall, lion predation and population trends in African herbivores. Proceedings of the Sixth International Theriological Congress, University of New South Wales in Sydney, Australia, Wildlife Res. 22, 75-88.

Morar, D., 2003. The development of an interferon-gamma (IFNg) assay for the diagnosis of tuberculosis in African elephants (Loxodonta africana) and black rhinoceros (Diceros bicornis). M.Sc. Thesis. Department of Veterinary Tropical Diseases, Faculty of Veterinary Sciences, University of Pretoria.
Morris, R.S., Pfeifer, D.U., 1994. The epidemiology of Mycobacterium bovis infections. Vet. Microbiol. 40, 153-177.

Osofsky, S.A., Cleaveland, S., Karesh, W.B., Kock, M.D., Nyhus, P.J., Starr, L., Yang, A. (Eds.), 2005. Proc. Southern and East African Experts Panel on Designing Successful Conservation and Development Interventions at the Wildlife/Livestock Interface: Implications for Wildlife, Livestock, and Human Health. AHEAD Animal Health for the Environment And Development) Forum. IUCN Vth World Parks Congress, Durban, South Africa, 14-15 September 2003. IUCN/SSC Veterinary Specialist Group, Southern Africa Sustainable Use Specialist Group, et al. IUCN, Gland, Switzerland and Cambridge, UK.

Paine, R., Martinaglia, G., 1929. Tuberculosis in wild buck living under natural conditions. J. Comp. Path. Ther. XLII (1), 1-8.

Phillips, C.J., Foster, C.R., Morris, P.A., Teverson, R., 2003. The transmission of Mycobacterium bovis infection to cattle. Res. Vet. Sci. 74, 1-15.

Raviglione, M.C., Snider, D.E., Kochi, A., 1995. Global epidemiology of tuberculosis. J. Am. Med. Assoc. 273, 220226.

Rodwell, T.C., Kriek, N.P., Bengis, R.G., Whyte, I.J., Viljoen, P.C., De Vos, V., Boyce, W.M., 2000. Prevalence of bovine tuberculosis in African buffalo at Kruger National Park. J. Wildlife Dis. 37, 258-264.

Rodwell, T.C., Whyte, I.J., Boyce, W.M., 2001. Evaluation of population effects of bovine tuberculosis in free-ranging African buffalo (Syncerus caffer). J. Mammal. 82, 231-238.

Schmitt, S.M., O'Brien, D.J., Bruning-Fann, C.S., Fitzgerald, S.D., 2002. Bovine tuberculosis in Michigan wildlife and livestock. Ann. NY Acad. Sci. 969, 262-268.

Thorburn, J.A., Thomas, A.D., 1940. Tuberculosis in Cape Kudu. J. S. Afr. Vet. Med. Assoc. 11, 3-10.

Walker, A.R.P., Walker, B.F., Wadee, A.A., 2003. The HIV/AIDS infection - the public health burden particularly in Southern Africa. S. Afr. J. Epidemiol. Infect. 18, 26-28.

Warren, R.M., Victor, T.C., Streicher, E.M., Richardson, M., Beyers, N., van Pittius, N.C., van Helden, P.D., 2004. Patients with active tuberculosis often have different strains in the same sputum specimen. Am. J. Respir. Crit. Care Med. 169, 610614.

Welsh, M.D., Cunningham, R.T., Corbett, D.M., Girvin, R.M., McNair, J., Skuce, R.A., Bryson, D.G., Pollock, J.M., 2005. Influence of pathological progression on the balance between cellular and humoral immune responses in bovine tuberculosis. Immunology 114, 101-111.

Whyte, I.J., 1998. Effects of bovine tuberculosis on the dynamics of the buffalo population in Kruger National Park. Preliminary Report. Scientific Report 07/1998. Kruger National Park, South Africa.

Woodford, M.H., 1972. Tuberculosis in the African buffalo (Syncerus caffer) in the Queen Elizabeth National Park, Uganda. Thesis presented to the Faculty of Veterinary Medicine of the University of Zurich for the Degree of Doctor of Veterinary Medicine. Juris Druck + Verlag, Zurich. 